Çukurova Üniversitesi Mühendislik Mimarlık Fakültesi Dergisi, 35(4), ss. 891-895, Aralık 2020

\title{
İnsansız Hava Aracı (İHA) ile Ortofoto ve Sayısal Yükseklik Modeli Üretimi: Adıyaman Üniversitesi Merkez Kampüs Örneği
}

\author{
Senem TEKIN ${ }^{*}{ }^{1}$, Fatih TEKIR ${ }^{2}$ \\ ${ }^{1}$ Adıyaman Üniversitesi, Teknik Bilimler Meslek Yüksek Okulu, Madencilik ve Maden Çıkarım \\ Bölümü, Adlyaman \\ ${ }^{2}$ Adlyaman Belediyesi, Imar ve Şehircilik Müdürlüğü, Adlyaman
}

Geliş tarihi: 02.12.2020 Kabul tarihi: 30.12 .2020

\section{Özet}

Uzaktan algılama (UA) ve Coğrafi Bilgi Sistemleri (CBS) teknolojilerindeki hızlı gelişim ile beraber İnsansız Hava Araçlarına (İHA) yönelik talep dünyada olduğu gibi ülkemizde de hızla artmaktadır. İHA ile elde edilen görüntülerin yüksek çözünürlük gibi özelliklere sahip olması yanı sıra arazi çalışması yapılması güç olan bölgelerde sağladığı büyük avantajları bulunmaktadır. Arazinin sahip olduğu morfolojiyi yansıtması ve elde edilen ortofotolardan elde edilen yüksek çözünürlüklü sayısal yükseklik modeli ve bu model kullanılarak elde edilen yamaç eğimi, yamaç yönelimi parametreleri ile bölgesel ya da alansal morfolojik özelliklerin ortaya çıkarılması çalışmalarında kullanılmaktadır. Bu çalışmada İHA kullanılarak Adıyaman Üniversitesi Merkez yerleşke kampüs civarını kapsayan yaklaşık 300 hektarlık bölgede, $3,41 \mathrm{~cm}$ hassasiyetinde ortofoto üretilmiştir. Bu görüntüyü kullanarak $3,41 \mathrm{~cm}$ hassasiyetinde sayısal yükseklik modeli, yamaç eğimi ve yamaç yönelimi haritaları elde edilmiştir.

Anahtar Kelimeler: Uzaktan algılama, Coğrafi bilgi sistemleri, İnsansız hava aracı, Adıyaman Üniversitesi

\section{Orthophoto and Digital Elevation Model Production using Unmanned Aerial Vehicle (UAV): Adıyaman University Main Campus}

\begin{abstract}
With the rapid development in Remote Sensing (RS) and Geographic Information Systems (GIS) technologies, the demand for Unmanned Aerial Vehicles (UAVs) is increasing rapidly in our country as in the world. In addition to the high resolution of the UAVs' images, they have great advantages in areas where it is challenging to do fieldwork. It is used to reflect the land's morphology and reveal the highresolution digital elevation model obtained from the mid-photos. The slope produced by this model, slope orientation parameters, and regional or spatial morphological features. In this study, an orthophoto with a sensitivity of $3.41 \mathrm{~cm}$ was produced in approximately 300 hectares covering the main campus of
\end{abstract}

*Sorumlu yazar (Corresponding author): Senem TEKIN, senemtekin@adiyaman.edu.tr 

Örneği

Adıyaman University using an UAV. Using these images, a digital elevation model with $3.41 \mathrm{~cm}$ precision, slope and slope orientation maps were obtained.

Keywords: Remote sensing, Geographic information systems, Unmanned aerial vehicles, Adryaman University

\section{GíRiș}

Uzaktan algılama (UA) ve Coğrafi Bilgi Sistemleri (CBS) teknolojilerindeki hızlı gelişim ile beraber İnsansız Hava Araçlarına (İHA) yönelik talep dünyada olduğu gibi ülkemizde de hizla artmaktadır [1,2]. 1979 yilında ilk kez İHA kullanılarak fotogrametrik denemeler yapılmıştır [3]. İHA'lar devlet kurumları, üniversiteler, özel şirketler, belediyeler ve akademik çevreler tarafından kullanılarak ihtiyaç doğrultusundaki tüm coğrafik verileri konumsal koordinatları yansitacak projeksiyon ve datum sistemlerini sunması sebebiyle tercih edilmektedir. Haritacılık konusunda, İHA gibi hava araçlarının pek çok avantajları bulunmaktadır [4,5]. Dolayısıyla, bu tür hava araçlarının kullanımı haritacılık anlamında pek çok avantajı beraberinde getirmektedir $[5,6]$. İHA'lara yerleştirilen dijital kameralar ürettikleri görüntüler ile arazi çalışmalarının zor/tehlikeli olabileceği bölgelerde ölçüm yapılabilme imkanı sunmaktadır [7,8]. En önemli avantajlarından biri ise, İHA yardımıyla üretillen ortofotolardain hassasiyet (yersel çözünürlük) bakımından yüksek doğruluk sunmasıdır. Uydu görüntülerinden daha yüksek hassasiyette görüntüler elde edilmektedir. Zamansal çözünürlük bakımından ise uygun hava koşullarında istenilen zamanlarda görüntü çekimi mümkündür.

$\mathrm{Bu}$ çalışmada, Adıyaman Ü̈niversitesi merkez kampüsü (Şekil 1) ve çevresine ait yaklaşık 300 hektarlık bir alanda İHA kullanılarak farklı yüzey örnekleme aralığı değerlerinde elde edilen üç bantlı görüntüler ile ortofotolar üretilmiştir. Bölgeye ait ortofoto, sayısal yükseklik modeli (SYM), nokta bulutu üretimi ile SYM kullanılarak yamaç eğimi, yamaç yönelimi gibi altlık parametreler oluşturulmuştur.

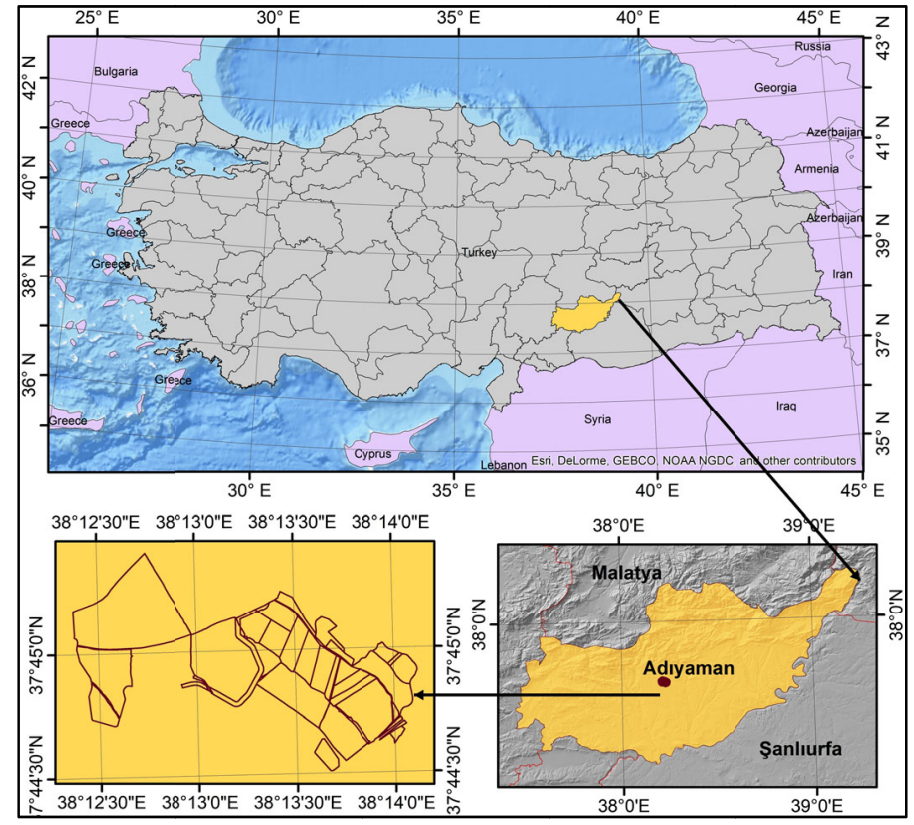

Şekil 1. Yer bulduru haritası 


\section{MATERYAL VE METOT}

$\mathrm{Bu}$ çalışma, Adıyaman Üniversitesi Merkez kampüsü içerisine alan yaklaşık 300 hektarlık alanda gerçekleştirilmiştir. Kampüs bölgesi ve çevresi düz bir morfolojiye sahip olması sebebiyle bina ve inşaat açısından yoğun aktivitenin olduğu bir bölgeyi içermektedir. Çalışmada, uçuş planı hazırlığı aşaması için Emotion 3.5; ve GNSS verilerini kullanılmas1 için Netcad; ortofotoların oluşturulması için Agisoft Metashape ile Pix4d yazılımları kullanılmıştır. Bölgenin topografik yapısının ortaya çıkarılması kapsamında ise SYM gibi mekansal parametreleri incelemek amaciyla ArcGIS yazılımı kullanılmıştır. Görüntü çekimi için FC6310R_8.8_5472x3648 (RGB) kamera kullanılmıştır. Y Yersel çözünürlük $3,41 \mathrm{~cm}$ (1,34 inç) olacak şekilde tercih edilmiştir. Çekilen her bir görüntü başına ortalama 53607 anahtar nokta oluşmuştur. Veri setinde 2886 görüntü bulunmaktadır. Tüm görüntülerin kalibrasyonu yapılmıştır. Kalibrasyon yapılan tüm görüntülerde ortalama 19014 eșleşme bulunmaktadır. Elde edilen $3,41 \mathrm{~cm}$ mekansal çözünürlükteki ortofolar görünür bantlar olan RGB (Kırmız1Yeşil-Mavi) bantlarını içermekte ve 8-bit radyometrik çözünürlüktedir (Çizelge 1).

Çizelge 1. Görüntüye ait teknik bilgiler

\begin{tabular}{|l|c|c|}
\hline Özellik & Ortofoto & $\begin{array}{c}\text { Sayısal } \\
\text { yükseklik } \\
\text { modeli }\end{array}$ \\
\hline Satır ve sütun & $2886 * 2886$ & $2886 * 2886$ \\
\hline Bant sayıs1 & 3 (RGB) & 1 \\
\hline Piksel türü & $\begin{array}{c}\text { Unsigned } \\
\text { Integer }\end{array}$ & $\begin{array}{c}\text { Unsigned } \\
\text { Integer }\end{array}$ \\
\hline $\begin{array}{l}\text { Radyometrik } \\
\text { çözünürlük }\end{array}$ & 8 bit & 32 bit \\
\hline $\begin{array}{l}\text { Koordinat } \\
\text { Sistemi }\end{array}$ & TUREF/TM39 & $\begin{array}{c}\text { TUREF/TM3 } \\
9\end{array}$ \\
\hline Zone & 37 & 37 \\
\hline
\end{tabular}

\section{BULGULAR}

11 Kasım 2020 tarihinde Planlanan uçuş doğrultusunda, \%65 enine ve boyuna bindirme şeklinde yer örneklem alanları belirlenmiştir (Şekil 2). Ek parametreler kullanılan yazılım ile otomatik olarak belirlenmiştir. Uçul 2 gün içerisinde tamamlanmıştır. Şekil 2'de ilk (mavi noktalar) ve hesaplanan (yeşil noktalar) görüntü konumlarının yanı sıra başlangıç konumları (mavi çarpılar) ve üstten görünümde (XY düzlemi), önden görünümde (XZ düzlemi) ve yandan görünümde (YZ düzlemi) hesaplanan konumları (yeşil çarpilar) görülmektedir. Şekil 2 deki mavi noktalar görüntü alınan alanları, yeşil noktalar ise kayıp görüntüleri ifade etmektedir. Fakat görüntüler $\% 65$ bindirmeli çekildiği için veri setinde herhangi bir boşluk alan oluşmamıştır. Görüntü çekimi $100 \quad \mathrm{~m}$ yükseklikten gerçekleştirilmiştir ve 288.6 fotograf elde edilmiştir. Tüm görüntüler kullanılarak kalibrasyon işlemi gerçekleştirilmiştir.

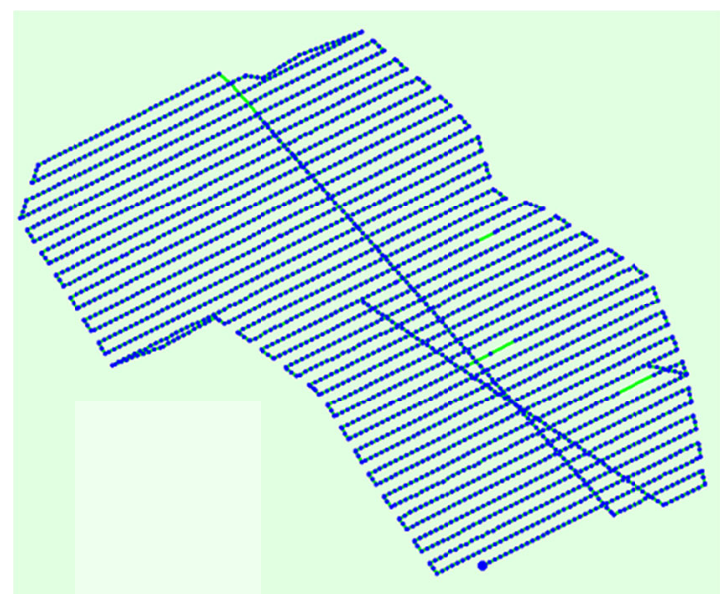

Şekil 2. Planlanan uçuş plan alanının üstten görünümü, Yeşil çizgi, büyük mavi noktadan başlayarak zaman içindeki görüntülerin konumunu takip eder

Doğrulama analizi sonrasında, Gerçek Zamanlı Kinematik (RTK) sistemi ile çekilen hava fotoğraflarının yersel çözünürlüğünün yeterli ölçüde olduğu hesaplanmıştır. Her bir yer örneklem alan değeri için nokta bulutu ve Ortofoto 

Örneği

görüntüleri (Şekil 3) hazırlanmıştır. Elde edilen ortofotonun yersel çözünürlüğünün $3.41 \mathrm{~cm}$ olması kampüs içerisindeki en küçük yapılması planlanan bir alan ölçümü için bile avantaj sağlamaktadır. Yükseklik değerleri en düşük $640 \mathrm{~m}$ en yüksek $750 \mathrm{~m}$ metre olup yaklaşık 110 metrelik yükselti değişimi görülmektedir (Şekil 4a). Yamaç eğim haritasına göre ise genellikle kampüsün düşük eğimli araziden oluştuğu görülmektedir. Kuzeydoğu bölgesinde bulunan dik yamaçlarda eğim değerleri yaklaşık $57^{\circ}$ ye ulaşmaktadır (Şekil 4b). Yamaç eğiminin azaldığı bölgelerde kuzeye doğru yaptığı açıyı ifade eden yamaç yönelimi haritasına göre yerleşke bölgesinin düz alanlardan oluştuğu fakat kuzeydoğu, güney ve güneydoğuya doğru yönelimin olduğu bölgeler olduğu görülmektedir (Şekil 4c).

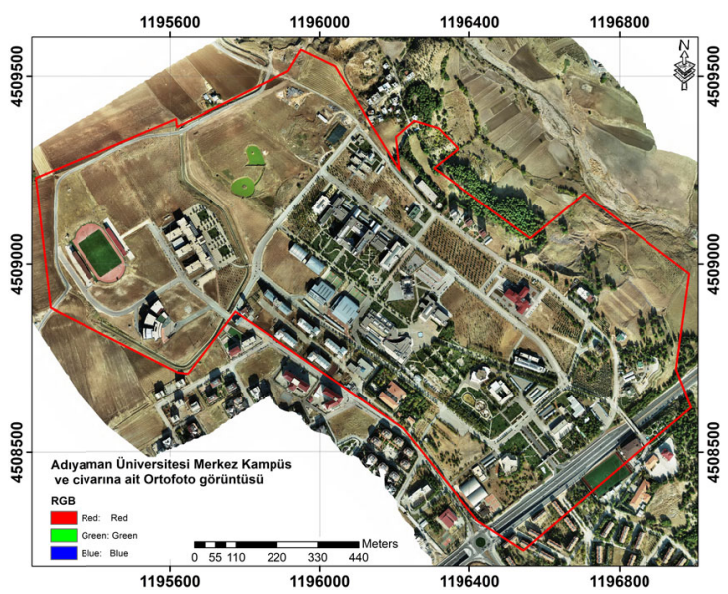

(a)

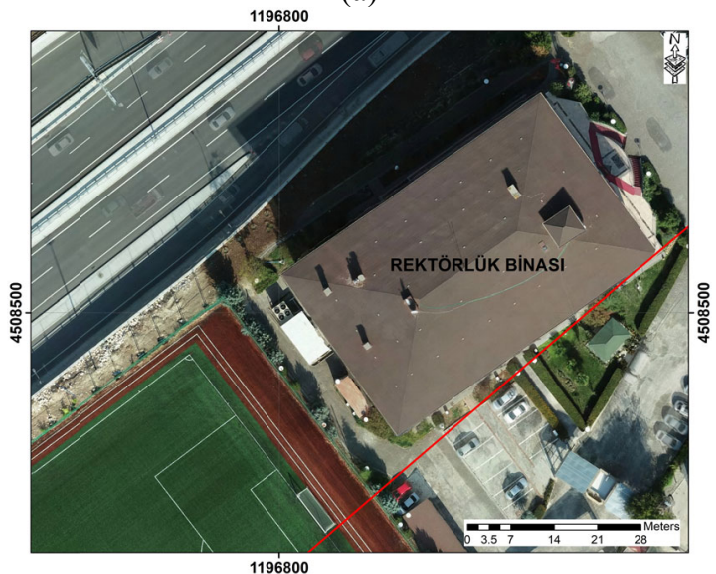

(b)

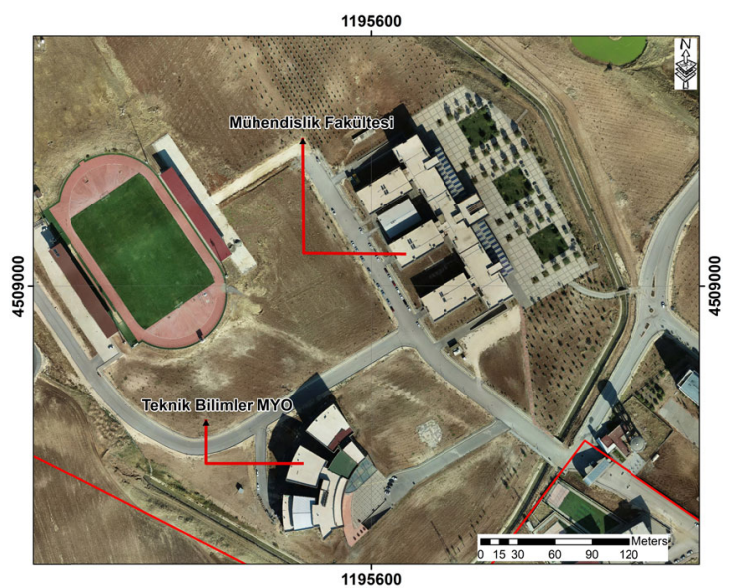

(c)

Şekil 3. Adıyaman Üniversitesi merkez kampüs yerleşkesi İHA ile elde edilen ortofoto görüntüsü (a), Rektörlük binası (b) ve bazı birimlerin (c) yakından görünümü

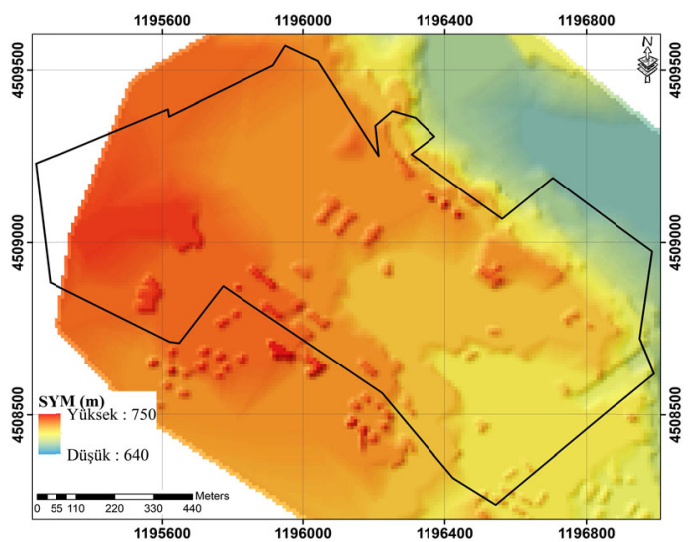

(a)

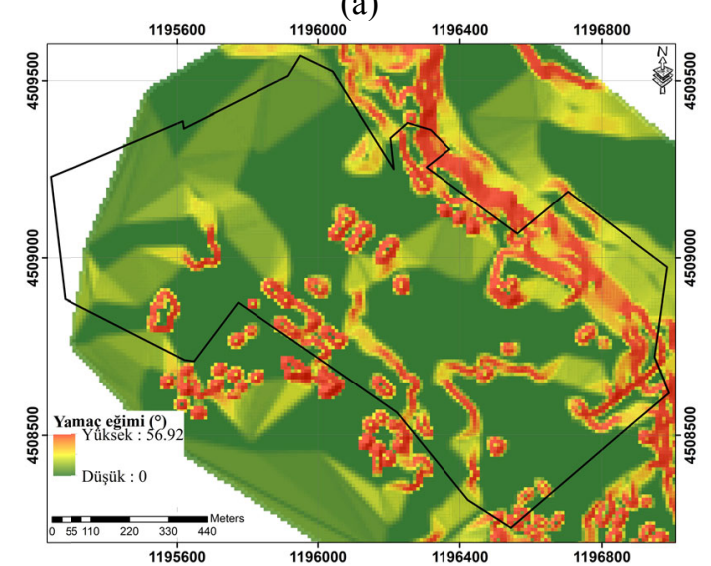

(b) 


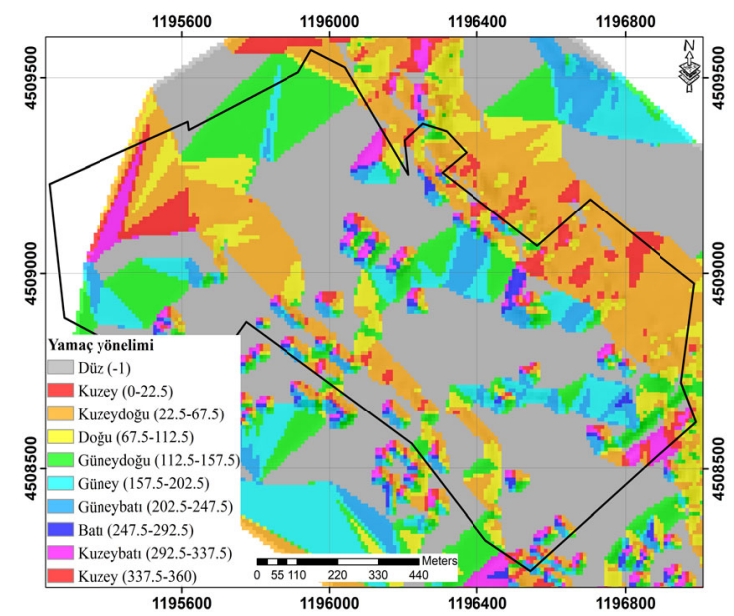

(c)

Şekil 4. Adıyaman Üniversitesi merkez kampüs yerleşkesi ve civarına ait sayısal yükseklik modeli (SYM) (a), Yamaç eğimi (b) ve yamaç yönelimi (c) haritaları

\section{SONUÇLAR}

Adıyaman Üniversitesi Merkez Kampüs Yerleşkesi'nde yapılan bu çalışma ile 3,41 cm konumsal hassasiyette ortofoto haritası üretilmiştir. $\mathrm{Bu}$ görüntü kullanılarak $10 \mathrm{~cm}$ hassasiyetinde yükseklik modeli üretilmiştir. Yükseklik modeli kullanılarak Adıyaman Üniversitesi Merkez kampüs için yamaç eğimi ve yamaç yönelimi haritaları oluşturulmuştur. Kampüs bölgesi ve civarı Adıyaman ili Merkez ilçe içerisinde yer alması ve düz bir morfolojiye sahip olması sebebiyle yerleşimin yoğunlaşmaya başladı̆̆ı bir bölgedir.

Sonuç olarak İHA ile elde edilen görüntülerin, yüksek çözünürlüklü, düşük maliyetli olması sebebiyle, fotogrametrik tekniklere sahip ortofotoların üretilmesine imkan sağlaması gibi avantajlarıda düşünüldüğünde haritacılık alanında büyük avantajlar sağlamaktadır. Üretilen veriler, Coğrafi Bilgi Sistemleri ile değerlendirildiğinde mühendislik, tasarım ve planlama süreçlerinde gelecekte yapılması planlanan halihazır haritalar için önemli bir altlı oluşturacağ düşünülmektedir.

\section{KAYNAKLAR}

1. Yılmaz, H.M., Mutluoğlu, Ö., Ulvi, A., Yaman, A., Bilgilioğlu, S.S., 2018. İnsansız Hava Aracı ile Ortofoto Üretimi ve Aksaray Üniversitesi Kampüsü Örneği, Geomatik dergisi, Journal of Geomatics, 3(2), 103-110.

2. Brutto, M.L., Garraffa, A., Meli, P., 2014. UAV Platforms for Cultural Heritage Survey: First Results. ISPRS Annals of the Photogrammetry, Remote Sensing and Spatial Information Sciences, Volume II-5, 2014 ISPRS Technical Commission V Symposium, 23 - 25 June 2014, Riva dell Garda, Italy.

3. Przybilla, H.J., Wester-Ebbinghaus, W., 1979. Bild Flug Mit Ferngelenktem Kleinflugzeug, In: Bildmessung und Luftbildwesen" Zeitschriftfuer Photogrammetrie und Fernerkudung, 47(5), 137-1.42.

4. Eisenbeis, H., 2009. UAV photogrammetry. Zurich, Switzerland: ETH.

5. Gökalp, E., Güngör, O., 2001. RTK (Real Time Kinematic) GPS'in İmar Uygulamalarında Kullanılması, TMMOB Harita ve Kadastro Mühendisleri Odas1 Dergisi, 87, 38-47.

6. Tekir, F., 2019. İnsansiz Hava Arac1 Görüntülerinden Bina Çatılarının Üç Boyutlu Çıkartılması, Yüksek Lisans Tezi, Yıldız Teknik Üniversitesi, Fen Bilimleri Enstitüsü, Harita Mühendisliği Anabilim Dalı, Uzaktan Algilama ve CBS Programı, İstanbul, 90.

7. Yılmaz, V., Akar, A., Akar, Ö., Güngör, O., Karslı, F., Gökalp, E., 2013. İnsansız Hava Arac1 ile Üretilen Ortofoto Haritalarda Doğruluk Analizi, Türkiye Ulusal Fotogrametri ve Uzaktan Algılama Birliği VII. Teknik Sempozyumu (TUFUAB’2013), 6, 23-25 Mayıs 2013, KTÜ, Trabzon.

8. Cilek, A., Berberoglu, S., Donmez, C.,Cilek, Unal, M., 2020. Generation of High-Resolution 3-D Maps for Landscape Planning and Design Using UAV Technologies, Journal of Digital Landscape Architecture, 5-2020, 275-284. 
